\title{
Inhibitive Protection of Low-Carbon Steel in Citric Acid Solutions
}

\author{
Yaroslav Avdeev ${ }^{1}$, Maria Tyurina ${ }^{1}$, Vladimir Rabinkov ${ }^{2, *}$, Andrei Luchkin ${ }^{1}$ \\ ${ }^{1}$ A.N. Frumkin Institute of Physical Chemistry and Electrochemistry, Russian Academy of Sciences, \\ Leninsky pr. 31, Moscow, 119071 Russian Federation \\ ${ }^{2}$ Moscow state university of civil engineering, Yaroslavskoye shosse, 26, Moscow, Russia, 129337
}

\begin{abstract}
An effective mixture has been developed on the basis of the inhibitor IFKhAN-92 and KCNS to protect low-carbon steel in citric acid hot solutions. The proposed mixture inhibits the corrosion of steel in these solutions in a wide range of their concentrations $(0.25 \div 2.0 \mathrm{M})$ and temperatures $\left(20 \div 95^{\circ} \mathrm{C}\right)$. The effective inhibition of the corrosion of steel by the mixture under study is due to the strong retardation of the metal's both electrode reactions.
\end{abstract}

\section{Introduction}

Thermal power equipment is chemically cleaned with citric acid solutions $\left(\mathrm{C}_{6} \mathrm{H}_{8} \mathrm{O}_{7}\right)$ before the launch (pre-operational chemical cleaning) to remove rust, scaling and other sediments and in the process of operation (operational cleanings) to remove iron oxide and carbonate (crust) formations [1-3]. These solutions demonstrate low aggressiveness towards steel equipment and remove roll scale, magnetite sediments and crust formations well, including through their complexing properties. Treatment with citrate solutions is quite frequently carried out at temperatures $(t)$ close to $100^{\circ} \mathrm{C}$. The solutions of other organic acids (adipic, maleic, oxalic, succinic) are less effective in thermal power equipment cleaning than citric acid solutions. Mixtures containing pyridine toxic derivatives - Catapin $\mathrm{K}$ and the inhibitor I-1-A [1], benzotriazol [4], cinnamic aldehyde [5] and various vegetal extracts [6-8] are recommended as additives to inhibit the corrosion of steels in citric acid solutions. In this case, benzotriazol, cinnamic aldehyde and vegetal extracts do not allow obtaining the metal protection degree of $Z>90 \%$. Lately, 1,2,4-triazole derivatives [9-11] have been gaining importance for protecting metals and alloys in mineral and organic acid solutions. The inhibitor of this class, IFKhAN-92, which we have developed, allows protecting low-carbon steel in mineral acids [12-14], and also in acetic and formic acid environments $[15,16]$. As its essential advantage, IFKhAN-92 is stable in hot acidic solutions.

It appeared expedient to develop an inhibitor based on IFKhAN-92, which is a substituted triazol, to protect low-carbon steel in citric acid hot solutions (up to $95^{\circ} \mathrm{C}$ ).

\footnotetext{
*Corresponding author: rabinkov@yandex.ru
} 


\section{Materials and methods}

\subsection{Gravimetric measurements}

The corrosion rate of low-carbon steel St3 in $\mathrm{C}_{6} \mathrm{H}_{8} \mathrm{O}_{7}$ solutions was measured by the mass loss of specimens (no less than three specimens per experimental point) sized $50 \mathrm{~mm} \times 20$ $\mathrm{mm} \times 1.5 \mathrm{~mm}$, using $30 \mathrm{ml}$ of the acid solution per specimen. Before the experiment, the specimens surface was conditioned by grinding on an abrasive disc (ISO 9001, 60 grit) and degreased with acetone. The duration of experiments was 2 hours.

The efficiency of inhibitors was estimated from the inhibition coefficient, $\gamma=k_{0} / k_{\text {in }}$, and the degree of protection $Z=\left[\left(k_{0}-k_{\text {in }}\right) / k_{0}\right] \cdot 100 \%$, where $k_{0}$ and $k_{\text {in }}$ are the corrosion rates in the non-inhibited solution and in the solution with the additive being studied, respectively. Coefficients of mutual influence were calculated to quantify the effect of inhibiting mixture components on the efficiency of the protection of steel:

$$
K_{\mathrm{m}}=\frac{\gamma_{\mathrm{mix}}}{\prod_{i=1}^{m} \gamma_{i}}
$$

where $\gamma_{\text {mix }}$ is the corrosion inhibition coefficient for the inhibitor mixture and $\prod_{i=1}^{m} \gamma_{i}$ is the product of the corrosion inhibition coefficients for individual mixture components. If $K_{\mathrm{m}}<$ 1 , the protection coefficient of the inhibitor components is mutually reduced; at $K_{\mathrm{m}}=1$, it shows an additive behavior; and only at $K_{\mathrm{m}}>1$ it should be concluded that the components of the inhibitor mixture mutually enhance protection.

Citric acid monohydrate (chemically clean) and distilled water were used to prepare solutions. KCNS (chemically clean) was studied as an additive to IFKhAN-92. Due to its low solubility, IFHAN-92 was introduced into $\mathrm{C}_{6} \mathrm{H}_{8} \mathrm{O}_{7}$ solutions in the form of an ethanol solution, with the ethanol concentration in the pickling solution equaling $0.24 \mathrm{~mol} / 1$.

\subsection{Electrochemical measurements}

Electrochemical measurements were carried out on a cylindrical electrode made of steel St3 $\left(0.72 \mathrm{~cm}^{2}\right)$ in the argon-deaerated $2.0 \mathrm{M} \mathrm{C}_{6} \mathrm{H}_{8} \mathrm{O}_{7}$ solutions at $t=95^{\circ} \mathrm{C}$. The steel electrode potentials were measured with reference to a silver chloride electrode and recalculated to the standard hydrogen electrode scale. The electrode that was preliminarily roughed up and degreased by acetone was held in the test solution for 30 minutes, after which the anodic and cathodic polarization curves were sequentially recorded with the help of the potentiostat IPC-PRO FM at a dynamic scan rate of $0.0005 \mathrm{~V} / \mathrm{s}$.

\section{Results and their discussion}

\subsection{Gravimetric measurements}

The corrosion of steel St 3 in $0.25 \div 2.0 \mathrm{M} \mathrm{C}_{6} \mathrm{H}_{8} \mathrm{O}_{7}$ solutions at a temperature of $t=20 \div 95^{\circ} \mathrm{C}$ occurs at a relatively low rate of no more than $106 \mathrm{~g} /\left(\mathrm{m}^{2} \cdot \mathrm{h}\right)$ (Table 1). The corrosion of steel accelerates with the increase of the concentration $C_{\mathrm{C} 6 \mathrm{H} 8 \mathrm{O} 7}$ and $t$ in the solution, which 
is consistent qualitatively with the data of the authors [3] on the study of the dissolution of low-carbon steels' kinetics in citric solutions.

Table 1. Corrosion rates $\left(k, \mathrm{~g} /\left(\mathrm{m}^{2} \cdot \mathrm{h}\right)\right)$ and corrosion inhibition coefficients $(\gamma)$ of steel St3 in citric acid solutions

\begin{tabular}{|c|c|c|c|c|c|c|c|c|}
\hline \multirow{3}{*}{ Inhibitor } & \multicolumn{8}{|c|}{ Acid concentration } \\
\hline & \multicolumn{2}{|c|}{$0.25 \mathrm{M}$} & \multicolumn{2}{|c|}{$0.50 \mathrm{M}$} & \multicolumn{2}{|c|}{$1.0 \mathrm{M}$} & \multicolumn{2}{|c|}{$2.0 \mathrm{M}$} \\
\hline & $k$ & $\gamma$ & $k$ & $\gamma$ & $k$ & $\gamma$ & $k$ & $\gamma$ \\
\hline \multicolumn{9}{|c|}{$20^{\circ} \mathrm{C}$} \\
\hline- & 1.93 & - & 1.95 & - & 1.98 & - & 2.01 & - \\
\hline $5.0 \mathrm{mM}$ IFKhAN-92 & 1.32 & 1.5 & 1.35 & 1.4 & 1.37 & 1.4 & 1.41 & 1.4 \\
\hline $5.0 \mathrm{mM} \mathrm{KCNS}$ & 1.96 & 0.98 & 2.01 & 0.97 & 2.15 & 0.92 & 2.21 & 0.91 \\
\hline $\begin{array}{c}4.5 \mathrm{mM} \text { IFKhAN-92 } \\
+0.5 \mathrm{mM} \mathrm{KCNS}\end{array}$ & 0.049 & 39.4 & 0.054 & 36.1 & 0.068 & 29.1 & 0.071 & 28.3 \\
\hline \multicolumn{9}{|c|}{$40^{\circ} \mathrm{C}$} \\
\hline- & 4.82 & - & 5.22 & - & 6.14 & - & 6.26 & - \\
\hline $5.0 \mathrm{mM}$ IFKhAN-92 & 3.51 & 1.4 & 3.56 & 1.5 & 3.64 & 1.7 & 3.70 & 1.7 \\
\hline $5.0 \mathrm{mM} \mathrm{KCNS}$ & 8.83 & 0.55 & 9.20 & 0.57 & 10.7 & 0.57 & 11.0 & 0.57 \\
\hline $\begin{array}{l}4.5 \mathrm{mM} \text { IFKhAN-92 } \\
+0.5 \mathrm{mM} \mathrm{KCNS}\end{array}$ & 0.21 & 23.0 & 0.23 & 22.7 & 0.27 & 22.7 & 0.29 & 21.6 \\
\hline \multicolumn{9}{|c|}{$60^{\circ} \mathrm{C}$} \\
\hline- & 15.1 & - & 17.6 & - & 19.5 & - & 22.5 & - \\
\hline $5.0 \mathrm{mM}$ IFKhAN-92 & 8.09 & 1.9 & 8.43 & 2.1 & 9.02 & 2.2 & 9.53 & 2.4 \\
\hline $5.0 \mathrm{mM} \mathrm{KCNS}$ & 17.3 & 0.87 & 18.3 & 0.96 & 19.2 & 1.0 & 20.3 & 1.1 \\
\hline $\begin{array}{l}4.5 \mathrm{mM} \text { IFKhAN-92 } \\
+0.5 \mathrm{mM} \mathrm{KCNS} \\
\end{array}$ & 0.29 & 52.1 & 0.30 & 58.7 & 0.33 & 59.1 & 0.35 & 64.3 \\
\hline \multicolumn{9}{|c|}{$80^{\circ} \mathrm{C}$} \\
\hline- & 30.3 & - & 39.7 & - & 45.2 & - & 52.5 & - \\
\hline $5.0 \mathrm{mM}$ IFKhAN-92 & 15.7 & 1.9 & 16.7 & 2.4 & 17.3 & 2.6 & 16.1 & 3.3 \\
\hline $5.0 \mathrm{mM} \mathrm{KCNS}$ & 34.9 & 0.87 & 40.5 & 0.98 & 44.5 & 1.0 & 44.4 & 1.2 \\
\hline $\begin{array}{c}4.5 \mathrm{mM} \text { IFKhAN-92 } \\
+0.5 \mathrm{mM} \mathrm{KCNS}\end{array}$ & 0.34 & 89.1 & 0.35 & 113 & 0.38 & 119 & 0.40 & 131 \\
\hline \multicolumn{9}{|c|}{$95^{\circ} \mathrm{C}$} \\
\hline- & 57.4 & - & 66.6 & - & 90.6 & - & 106 & - \\
\hline $5.0 \mathrm{mM}$ IFKhAN-92 & 24.1 & 2.4 & 26.9 & 2.5 & 30.8 & 2.9 & 34.6 & 3.1 \\
\hline $5.0 \mathrm{mM} \mathrm{KCNS}$ & 62.1 & 0.92 & 70.4 & 0.95 & 78.8 & 1.1 & 85.0 & 1.2 \\
\hline $\begin{array}{l}4.5 \mathrm{mM} \text { IFKhAN-92 } \\
+0.5 \mathrm{mM} \mathrm{KCNS} \\
\end{array}$ & 0.43 & 133 & 0.50 & 133 & 0.55 & 165 & 0.57 & 185 \\
\hline
\end{tabular}

The addition of $5.0 \mathrm{mM}$ IFKhAN-92 to $0.25 \div 2.0 \mathrm{M} \mathrm{C}_{6} \mathrm{H}_{8} \mathrm{O}_{7}$ solutions weakly reduces $k$ of steel: $Z_{\text {IFKhAN-92 }}=29 \div 70 \%$. One of the methods to enhance the inhibitory effect of IFKhAN-92 in mineral acid solutions is to add hydrophobic compounds, among which KCNS is distinguished, which we successfully used for the protection of steel in phosphoric acid media $[17,18]$. Such additive itself either stimulates the corrosion of steel or slightly inhibits it with the value of $Z \leq 17 \%$. The additive's maximum stimulating effect is observed at $t=40^{\circ} \mathrm{C}$.

In the presence of $4.5 \mathrm{mM}$ IFKhAN-92 $+0.5 \mathrm{mM} \mathrm{KCNS}$ in $\mathrm{C}_{6} \mathrm{H}_{8} \mathrm{O}_{7}$ solutions, the corrosion of steel was significantly slowed down: $Z=96 \div 99 \%$. In this case, the corrosion rate of steel in acid solutions inhibited by this mixture did not exceed $0.57 \mathrm{~g} /\left(\mathrm{m}^{2} \cdot \mathrm{h}\right)$. With $t$ $>40^{\circ} \mathrm{C}$, the $\gamma$ values of the mixture of inhibitors grow systematically with the increase of $t$. It is important to note that the temperature peak of the inhibition efficiency of the IFKhAN92 and KCNS mixture was not reached in the tested range of $t$. The increase of $t$ by $75^{\circ} \mathrm{C}$ 
increases the value of $\gamma$ by $3.4 \div 6.5$ times. The mixture's protective effect at $t=20 \div 40^{\circ} \mathrm{C}$ decreases with the growth of $C_{\mathrm{C} 6 \mathrm{H} 8 \mathrm{O} 7}$ and, on the contrary, rises at higher $t$.

The mixture of IFKhAN-92 and KCNS displays the synergism of components, with $K_{\mathrm{m}}$ demonstrating quite high values (Table 2). It intensifies with the increase of $t$ and declines with the increase of $C_{\mathrm{C} 6 \mathrm{H} 807}$.

Table 2. Coefficients of mutual influence of $4.5 \mathrm{mM}$ IFKhAN-92 and $0.5 \mathrm{mM}$ KCNS components in corrosion of steel St3 in citric acid solutions

\begin{tabular}{|c|c|c|c|c|}
\hline \multirow{2}{*}{$t,{ }^{\circ} \mathrm{C}$} & \multicolumn{4}{|c|}{ Acid concentration } \\
\cline { 2 - 5 } & $0.25 \mathrm{M}$ & $0.5 \mathrm{M}$ & $1.0 \mathrm{M}$ & $2.0 \mathrm{M}$ \\
\hline 20 & 27 & 27 & 23 & 22 \\
\hline 40 & 30 & 27 & 23 & 22 \\
\hline 60 & 32 & 29 & 27 & 24 \\
\hline 80 & 54 & 48 & 46 & 33 \\
\hline 95 & 60 & 56 & 52 & 50 \\
\hline
\end{tabular}

The inhibitive mixture under study retains its protective effect in citric acid solutions during at least 6 days (Table 3). Over this time, the rate of corrosion in the base solution decreases by 14.4 times and in the presence of $4.5 \mathrm{mM}$ IFKhAN-92 $+0.5 \mathrm{mM} \mathrm{KCNS}$ it declines slightly less - by 7.7 times. A marked decrease in the $\gamma$ value of the inhibitive mixture is observed only on the 6th day of observations.

Table 3. Corrosion rates of steel St $3\left(k, \mathrm{~g} /\left(\mathrm{m}^{2} \cdot \mathrm{h}\right)\right)$ and coefficients of corrosion inhibition $(\gamma)$ in $2.0 \mathrm{M}$ citric acid inhibited by $4.5 \mathrm{mM}$ IFKhAN-92 and $0.5 \mathrm{mM}$ KCNS mixture at specimens' different exposure time. $t=20^{\circ} \mathrm{C}$

\begin{tabular}{|c|c|c|c|c|c|c|c|c|c|c|}
\hline \multirow{2}{*}{ Inhibitor } & $k$, & \multicolumn{10}{|c|}{ Specimen exposure time, $\mathrm{h}$} \\
\cline { 3 - 12 } & $\gamma$ & 0.5 & 1.0 & 2 & 4 & 10 & 24 & 48 & 96 & 144 \\
\hline- & $k$ & 3.32 & 2.96 & 2.01 & 1.42 & 0.79 & 0.48 & 0.34 & 0.29 & 0.23 \\
\hline $\begin{array}{c}\text { IFKhAN-92 } \\
+ \text { KCNS }\end{array}$ & $k$ & 0.10 & 0.09 & 0.071 & 0.051 & 0.029 & 0.018 & 0.013 & 0.012 & 0.013 \\
\cline { 2 - 12 } & $\gamma$ & 33.2 & 32.9 & 28.3 & 27.8 & 27.2 & 26.7 & 26.2 & 24.2 & 17.7 \\
\hline
\end{tabular}

The IFKhAN-92 + KCNS mixture with fixed $C_{\mathrm{KCNS}}=0.5 \mathrm{mM}$ demonstrates an $S$ shaped dependence of $Z_{\text {mix }}$ on IFKhAN-92 concentration (Fig. 1). The values of $Z \geq 90 \%$ are reached at $C_{\text {IFKhAN-92 }} \geq 0.1 \mathrm{mM}$, which, based on the shape of experimental $Z_{\text {mix }}$ $C_{\text {IFKhAN-92 }}$ dependencies, corresponds to the maximum coverage of the metal's surface with the inhibitor. With $C_{\mathrm{IFKhAN}-92}<0.01 \mathrm{mM}$, the mixture loses its protective effect and can stimulate corrosion. We discussed the nature of the stimulating effect of low $C_{\text {IFKhAN-92 }}$ values on the corrosion of metal in acids earlier [19] and it is most probably related to the solution's surface tension weakened by this inhibitor, which facilitates the removal of hydrogen bubbles from the metal's surface. 


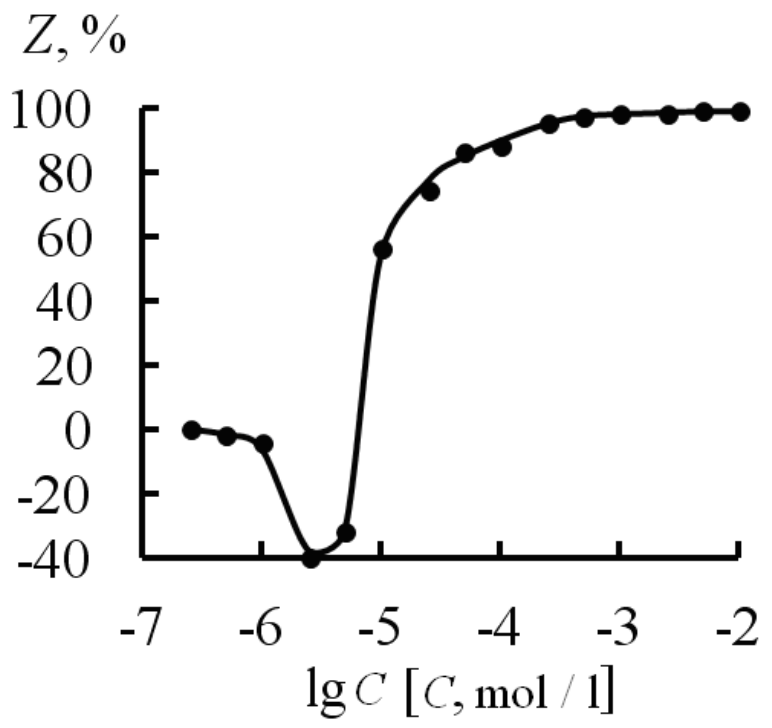

Fig. 1. Dependence of the degree of protection by IFKhAN-92 + KCNS $(0.5 \mathrm{mM})$ mixture on IFKhAN-92 concentration for St3 steel corrosion in $2.0 \mathrm{M} \mathrm{C}_{6} \mathrm{H}_{8} \mathrm{O}_{7}$ at $60^{\circ} \mathrm{C}$

The same mixture with $C_{\text {IFKhAN-92 }}=5.0 \mathrm{mM}$ also manifests an $S$-shaped dependence of $Z_{\text {mix }}$ on $C_{\mathrm{KCNS}}$ (Fig. 2). This composition loses its efficiency at $C_{\mathrm{KCNS}}<0.05 \mathrm{mM}$ in comparison with $5.0 \mathrm{mM}$ IFKhAN-92. The maximum protective effect of the $5.0 \mathrm{mM}$ IFKhAN-92 + KCNS mixture is observed at $C_{\mathrm{KCNS}}=0.25 \mathrm{mM}(\gamma=98)$. A further increase in $C_{\mathrm{KCNS}}$ decreases $\gamma$. For example, $\gamma_{\text {mix }}$ for the mixture of $5.0 \mathrm{mM}$ IFKhAN-92 $+10.0 \mathrm{mM}$ $\mathrm{KCNS}$ is 1.6 times lower.

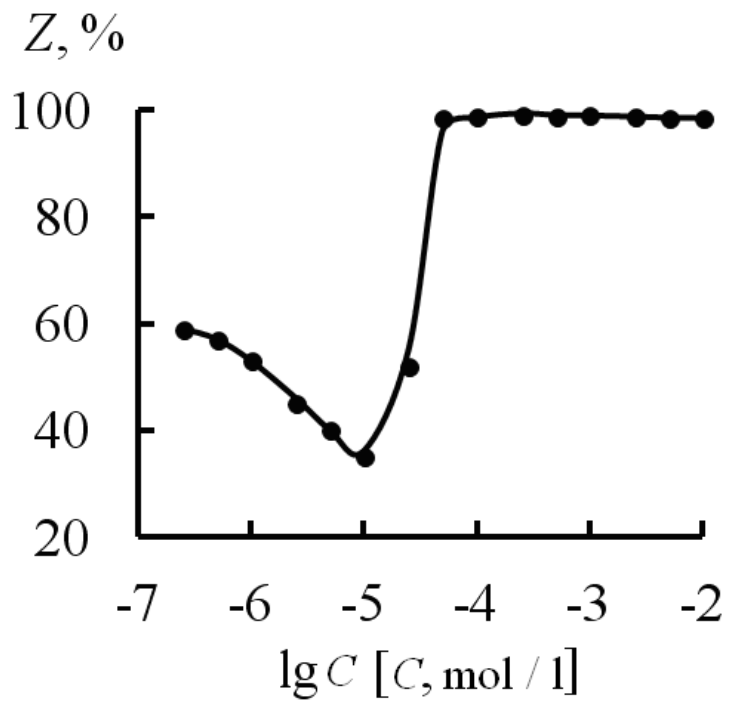

Fig. 2. Dependence of the degree of protection by IFKhAN-92 $(5.0 \mathrm{mM})$ and KCNS mixture on KCNS concentration for $\mathrm{St} 3$ steel corrosion in $2.0 \mathrm{M} \mathrm{C}_{6} \mathrm{H}_{8} \mathrm{O}_{7}$ at $60^{\circ} \mathrm{C}$ 


\subsection{Electrochemical measurements}

The electromechanical measurements performed on steel in $2.0 \mathrm{M} \mathrm{C}_{6} \mathrm{H}_{8} \mathrm{O}_{7}\left(t=95^{\circ} \mathrm{C}\right)$ have shown that the use of the $5.0 \mathrm{mM}$ KCNS additive in the solution somewhat slows down the cathodic reaction of steel and disinhibits the anodic reaction probably due to the participation of rhodanide anion in this process as a complexing reagent (Fig. 3). Addition of $5.0 \mathrm{mM}$ IFKhAN-92 refines the corrosion potential $\left(E_{\text {cor }}\right)$, inhibiting mainly the anodic process. The use of the $4.5 \mathrm{mM}$ IFKhAN-92 $+0.5 \mathrm{mMKCNS}$ mixture causes a considerably stronger increase in $E_{\text {cor }}$, and also the inhibition of the cathodic and especially the anodic reaction. Therefore, the corrosion of steel in $\mathrm{C}_{6} \mathrm{H}_{8} \mathrm{O}_{7}$ solutions is inhibited more effectively by the IFKhAN-92 + KCNS mixture due to the stronger inhibition of the metal's electrode reactions by this mixture compared to its components.

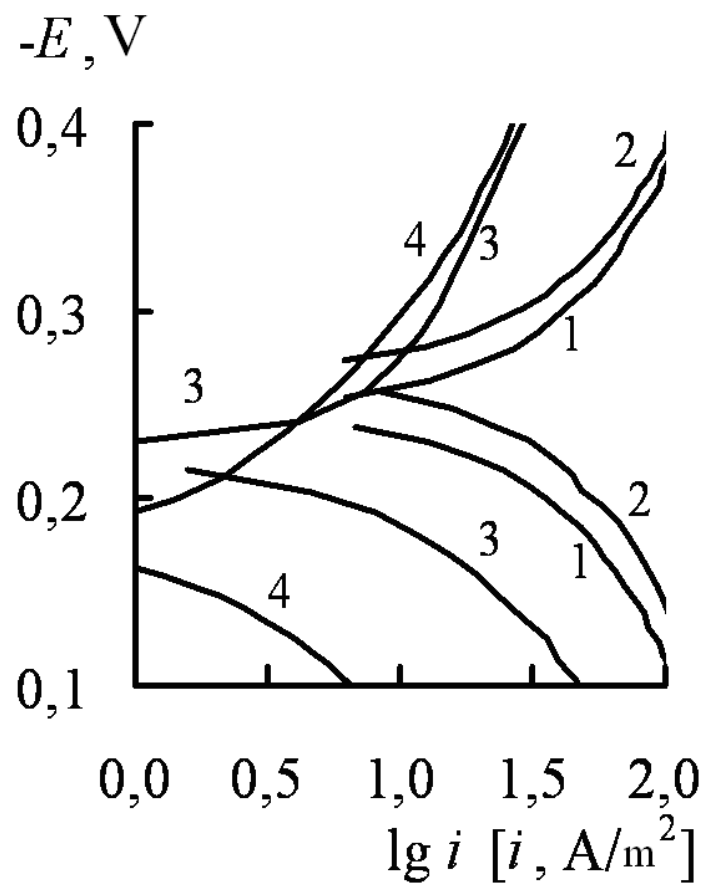

Fig. 3. Steel St 3 polarization curves in $2.0 \mathrm{M} \mathrm{C6H8O} 7$ (1) in the presence of: $2-5.0 \mathrm{mM} \mathrm{KCNS}, 3-$ $5.0 \mathrm{mM}$ IFKhAN-92, $4-4.5 \mathrm{mM}$ IFKhAN-92 $+0.5 \mathrm{mM} \mathrm{KCNS} . \mathrm{t}=95^{\circ} \mathrm{C}$

\section{Conclusions}

4.1 The IFKhAN-92 metal acid corrosion inhibitor can be successfully used in a mixture with the KCNS additive for protecting low-carbon steel in citric acid solutions in a wide range of its concentrations $(0.25 \div 2.0 \mathrm{M})$ and temperatures $\left(20 \div 95^{\circ} \mathrm{C}\right)$ during a long period of time.

4.2 The effective inhibition of the corrosion of steel in citric acid solutions by the IFKhAN-92 + KCNS mixture occurs due to the strong inhibition of the metal's both electrode reactions by this mixture. 


\section{References}

1. Ivanov E.S., Ingibitory korrozii metallov v kislyh sredah (Ye.S. Ivanov, Inhibitors of Metals Corrosion in Acid Media), in Reference Book, Metallurgiya, Moscow, (1986) pp. 112-118 (in Russian).

2. Rozenfel'd I.L., Ingibitory korrozii (I.L. Rozenfeld, Corrosion Inhibitors), in Khimiya, Moscow (1977) pp. 235-242 (in Russian).

3. Fateev V.D., Klyuchnikov N.G., Izuchenie rastvoreniya kotel'nyh stalej i okislov zheleza v rastvorah limonnoj kisloty (V.D. Fateyev, N.G. Klyuchnikov, Study of the Dissolution of Boiler Steel and Iron Oxides in Citric Acid Solutions), in Ingibitori Korrozii Metallov, Sudostroyeniye, Moscow (1965) pp. 192-209 (in Russian).

4. Matheswaran P., Ramasamy A.K., Influence of Benzotriazole on Corrosion Inhibition of Mild Steel in Citric Acid Medium, in E-Journal of Chemistry (2010) V. 7 (3), pp. 1090-1094.

5. Sathiya Priya A.R., Muralidharan S., Velmurugan S., Venkatachari G., Corrosion inhibitor for the chemical decontamination of primary coolant systems of nuclear power plants, in Materials Chemistry and Physics (2008) V. 110, pp. 269-275.

6. Matheswaran P., Ramasamy A.K., Corrosion Inhibition of Mild Steel in Citric Acid by Aqueous Extract of Piper Nigrum L., in E-Journal of Chemistry (2012) V. 9 (1), pp. 75-78.

7. Alka Singh, Kalpana S., Inhibition of the Corrosion of Iron in Citric acid solutions by Aqueous extract of Fenugreek seeds, in Ultra Chemistry, India, Bhopal, 2012, V. 8 (2), pp. 175-179.

8. Anand B., Balasubramanian V., Corrosion Behaviour of Mild Steel in Acidic Medium in Presence of Aqueous Extract of Allamanda Blanchetii, in E-Journal of Chemistry (2011) V. 8 (1), pp. 226-230.

9. Ya.G. Avdeev, Yu.I. Kuznetsov, Physicochemical aspects of inhibition of acid corrosion of metals by unsaturated organic compounds, Russ. Chem. Rev., 81 (2012) 1133-1145.

10. Korolchenko, D., Tusnin, A., Trushin, S., Korolchenko, A. Physical parameters of high expansion foam used for fire suppression in high-rise buildings. (2015) International Journal of Applied Engineering Research, 10 (21), pp. 42541-42548.

11. Sharovarnikov A.F., Korol'chenko D.A., Fighting fires of carbon dioxide in the closed buildings // Applied Mechanics and Materials (2014) Vol. 475-476. - P.1344-1350.

12. Avdeev YA.G., Luchkin A.YU., Kuznecov YU.I., Gorichev I.G., Tyurina M.V., Zashchita nizkouglerodistoj stali $\mathrm{v}$ serno-kislyh rastvorah ot vysokotemperaturnoj korrozii (do 200C) (Ya.G. Avdeev, A.Yu. Luchkin, A.Yu. Kuznetsov, I.G. Gorichev, M.V. Tyurina, Protection of Low-Carbon Steel in Sulphuric Acid Solutions from HighTemperature Corrosion (up to 200 $\square$ C)), in Korroz.: mater., zashch., Moscow (2011) No. 8, pp. 20-26 (in Russian).

13. Avdeev YA.G., Luchkin A.YU., Kuznecov YU.I., Gorichev I.G., Tyurina M.V., Zashchita nizkouglerodistoj stali $\mathrm{V}$ solyanokislyh rastvorah $\mathrm{V}$ usloviyah vysokotemperaturnoj korrozii (do 160C) (Ya.G. Avdeev, A.Yu. Luchkin, Yu.I. Kuznetsov, I.G. Gorichev, M.V. Tyurina, Protection of Low-Carbon Steel in Hydrochloric Acid Solutions in the Conditions of High-Temperature Corrosion (up to $160 \square$ C)), in Korroz.: mater., zashch., Moscow (2011) No. 10, pp. 26-31 (in Russian).

14. Shebeko, Yu.N., Smolin, I.M., Korolchenko, A.Ya., Shevchuk, A.P., Borodkin, A.N., Malkin, V.L., Simonov, O.A., Gurinovich, L.V., Popov, S.A., Kolosov, V.A., Smirnov, E.V. Some aspects of fire and explosion hazards of large LPG storage vessels. (1995) Journal of Loss Prevention in the Process Industries, 8 (3), pp. 163-168. DOI: 10.1016/0950-4230(95)00011-O. 
15. Avdeev YA.G., Kuznecov YU.I., Tyurina M.V., Ob ingibirovanii korrozii nizkouglerodistoj stali $\mathrm{v}$ goryachih rastvorah organicheskih kislot (Ya.G. Avdeeev, Yu.I. Kuznetsov, M.V. Tyurina, Inhibition of Low-Carbon Steel Corrosion in Hot Solutions of Organic Acids) in Korroz.: mater., zashch., Moscow (2012) No. 3, pp. 2428 (in Russian).

16. Shebeko, Yu.N., Tsarichenko, S.G., Trunev, A.V., Korolchenko, A.Ya., Kaplin, A.Yu. The influence of inert retardants on the combustion of hydrogen-oxygen mixtures under elevated temperatures and pressures. (1994) Combustion, Explosion, and Shock Waves, 30 (2), pp. 183-188. DOI: 10.1007/BF00786125

17. Avdeev YA.G., Kuznecov YU.I., Tyurina M.V., Zashchita nizkouglerodistoj stali v rastvorah fosfornoj kisloty ingibitorom IFHAN-92. CH. 1 (Ya.G. Avdeev, Yu.I. Kuznetsov, M.V. Tyurina, Low-Carbon Steel Protection in Phosphoric Acid Solutions by the IFKhAN-92 Inhibitor. Part 1) in Korroz.: mater., zashch., Moscow (2012) No. 5, pp. 22-26 (in Russian).

18. Shebeko, Yu.N., Tsariichenko, S.G., Korolchenko, A.Ya., Erofeev, A.N. Characteristics of combustion of hydrogen - methane - air mixtures in a closed vessel. (1991) Fizika Goreniya i Vzryva, (6), pp. 52-56.

19. Avdeev YA.G., Belinskij P.A., Kuznecov YU.I., Zel' O.O., Zashchita stali ot sernokislotnoj korrozii ingibitorom IFHAN-92 (Ya.G. Avdeev, P.A. Belinsky, Yu.I. Kuznetsov, O.O. Zel', Protection of Steel from Sulfuric Acid Corrosion by the IFKhAN-92 Inhibitor), in Korroz.: mater., zashch., Moscow (2008) No. 8, pp. 16-21 (in Russian). 